\title{
Effects of Exercise on Lung Lymph Flow in Sheep and Goats during Normoxia and Hypoxia
}

G. Coates, H. O'Brodovich, A. L. Jefferies, and G. W. Gray Departments of Radiology and Paediatrics, McMaster University Faculty of Health Sciences, Hamilton, Ontario, Canada, L8N 3Z5; Defense and Civil Institute of Environmental Medicine, Downsview, Ontario, Canada, M3M $3 B 9$

bstract. Vigorous exercise causes a marked increase in cardiac output with only a minimal increase in measureable pulmonary vascular pressures. These changes in pulmonary hemodynamics should affect lung water and solute movement.

On nine occasions, we measured the effect of normoxic exercise on lung lymph flow in four sheep and two goats with chronic lymph fistulas (wt $=15-25 \mathrm{~kg}$ ). In addition, lymph flow was also measured on five occasions in sheep during exercise at reduced barometric pressures (430 and $380 \mathrm{mmHg}$ ). During normobaria, the animals ran at 3$5 \mathrm{~km} / \mathrm{h}$ with $0-10 \%$ elevation of the treadmill for 15 to $85 \mathrm{~min}$. Exercise on average caused a $100 \%$ increase in cardiac output, a $140 \%$ increase in lung lymph flow, and a slight but significant reduction in lymph to plasma concentration ratio $(1 / \mathrm{p})$ for total protein and albumin $(\mathrm{mol}$ $w t=70,000)$. There was a significant linear correlation between lymph flow and cardiac output $(r=0.87, P$ $<0.01$ ). There was no change in $1 / \mathrm{p}$ for $\mathrm{IgG}$ (mol wt $=150,000)$ or IgM $(\mathrm{mol} \mathrm{wt}=900,000)$ and no significant change in mean pulmonary arterial $(\overline{\mathrm{P}} \mathrm{pa})$ or mean left atrial (Pla) pressures. Transition from normobaria to hypobaria caused an increase in $\overline{\mathrm{P}}$ pa but no change in $\overline{\mathrm{P}} \mathrm{la}$, cardiac output, or lymph flow. Exercise during hypobaria caused increases in lymph flow that were qualitatively similar to changes observed during normobaric exercise:

These investigations were presented in part at the American Lung Association Annual Meeting in Kansas City, April 1983.

Dr. Jefferies is a Fellow of the Medical Research Council of Canada and Dr. O'Brodovich is a Scholar of the Canadian Heart Foundation. Address all correspondence and reprint requests to Dr. Coates, Department of Nuclear Medicine, McMaster University Medical Center, Hamilton, Ontario, Canada, L8N 3Z5.

Received for publication 10 November 1983 and in revised form 29 March 1984.

J. Clin. Invest.

(C) The American Society for Clinical Investigation, Inc.

0021-9738/84/07/0133/09 \$1.00

Volume 74, July 1984, 133-141 there was a $60 \%$ increase in cardiac output, a $90 \%$ increase in lymph flow, and an $11 \%$ reduction in $1 / p$ for total protein. There was no change in $1 / p$ for albumin, $\mathrm{IgG}$, or IgM, and no further change in Ppa. The increased lymph flow during normoxic and hypobaric exercise is best explained by an increase in pulmonary vascular surface area for fluid and protein exchange. Our results suggest that the normal ovine lung has the potential to nearly triple the amount of perfused microvascular surface area. This speculation is relevant to the interpretation of lymph flow data from other experiments.

\section{Introduction}

The effect of exercise on lung water and solute movement is unknown. Vigorous exercise causes a marked increase in cardiac output, a minimal increase in pulmonary arterial pressure (13 ), and a decrease in calculated pulmonary vascular resistance. The reduction in resistance to blood flow through the lung during exercise results from pulmonary vascular recruitment and or dilatation and an increase in perfused microvascular surface area (2-6). This, in turn, should cause an increased exchange of fluid across the pulmonary capillaries with a concomitant increase in lymph flow from the lungs. It is also possible that an increase in fluid movement could result from a greater transmission of upstream pressure to the fluid exchange vessels of the lungs. While there is evidence that exercise causes an increase in lymph flow from the limbs (7) and heart (8), there are no published data on the effect of exercise on lung lymph flow. There is, however, indirect evidence in animals (9) and man that exercise with $(10,11)$ or without $(12-16)$ hypobaric hypoxia causes an increase in extravascular lung water. There are also reports of acute pulmonary edema occurring in man during very vigorous exercise at sea level (17) and during moderate exercise at high altitude (18-20).

The experiments that we will describe were carried out to determine the effect of exercise on lung lymph flow during normoxic and hypobaric hypoxic conditions. In addition, assuming that exercise is not associated with an increase in lung vascular permeability, these studies were also performed to assess the potential of the pulmonary circulation to increase surface 
area for fluid exchange. These data might reinforce the effect of changes in surface area when analyzing data from experiments where lymph flow increases as a result of changes in the permeability-surface area product.

\section{Methods}

Animal preparation. We prepared chronic lymph fistulae and placed vascular catheters in two goats and four sheep (15-25 kg) using a modification of the method described by Staub and co-workers (21). In brief, through a right thoracotomy, we isolated the efferent duct of the caudal mediastinal lymph node and in it positioned a catheter of Dow Corning medical grade silastic tubing (0.25-0.3 mm diameter) (Dow Corning Corp., Midland, MI). Through a second right thoracotomy, the posterior end of the lymph node was isolated, tied tightly twice with umbilical tape, and transected. On a separate day, through a left thoracotomy, the left and right atria were catheterized with medical grade polyethylene tubing and a thermistor-tipped catheter was positioned in the pulmonary artery. The carotid artery was also catheterized. To further minimize contamination of lung lymph with systemic lymph, we cauterized the pleural surface of both hemi-diaphragms. The animals were allowed to recover from surgery and were studied at 4-14 $d$ later.

Experimental protocol. During the normoxic experiments, we measured vascular pressures with Statham P23ID transducers interfaced to a multichannel recorder. In the hypobaric hypoxic experiments, we measured mean pulmonary arterial and left atrial pressure with salinefilled manometers, and measured pressures were subsequently converted to $\mathrm{mmHg}$. These pressure monitors were zeroed to the sternum. Cardiac output was measured by thermodilution with an Edwards 9520A cardiac output computer (Edwards Laboratories, Santa Ana, CA). At predetermined time points, we obtained arterial and mixed venous blood samples for measurement of blood gas tensions, $\mathrm{pH}$, and plasma lactate (mixed venous only). Plasma lactate was measured by the enzymatic technique utilizing lactate dehydrogenase. Blood gas tensions and $\mathrm{pH}$ were measured at $37^{\circ} \mathrm{C}$. We measured total protein by refractrometry, and albumin $(\mathrm{mol} \mathrm{wt}=70,000), \operatorname{IgG}(\mathrm{mol} \mathrm{wt}=150,000)$, and $\operatorname{IgM}(\mathrm{mol} \mathrm{wt}=900,000)$ by radial immunodiffusion in plasma and lymph $(22,23)$. Lymph flow was measured from timed collections.

Normoxic exercise. Nine experiments were performed in two goats and four sheep. All of the above measurements were made at 30-min intervals for a base-line period of 1-2 $\mathrm{h}$. The animals then exercised on a modified Quinton 14-44A treadmill (Quinton Instruments, Seattle, WA) at $3-5 \mathrm{~km} / \mathrm{h}$ and $0-10 \%$ elevation. The speed and elevation were varied according to the individual animals' tolerance and resulted in a fast trot for the size of animals that we used. The measurements were made at 10-min intervals until the animal would no longer run, and then continued for $20 \mathrm{~min}$ after the treadmill was turned off. These experiments were performed at McMaster University (elevation $=100$ $\mathrm{m}$; average atmosphere pressure $=750 \mathrm{mmHg}$ ).

Hypobaric hypoxia. To investigate the combined effect of hypoxia and exercise on lung lymph flow, we performed additional experiments under simulated high altitude conditions. These hypobaric experiments were performed in the hypobaric chamber at the Defense and Civil Institute of Environmental Medicine, Downsview, Ontario (altitude $=150 \mathrm{~m}$, average atmospheric pressure $=746 \mathrm{mmHg}$ ). After $2 \mathrm{~h}$ of base-line measurements, the chamber was decompressed to the predetermined pressure at a rate equivalent to $300 \mathrm{~m} / \mathrm{min}$.

Five experiments were performed in two sheep on five separate occasions. Measurements were made during exercise in two animals after 2-3 $\mathrm{h}$ at barometric pressure of $430 \mathrm{mmHg}$ (equivalent altitude, $4,550 \mathrm{~m}$ ), in two animals after $24 \mathrm{~h}$ at $430 \mathrm{mmHg}$, and in one animal after $24 \mathrm{~h}$ at $380 \mathrm{mmHg}$ (equivalent altitude, $5,500 \mathrm{~m}$ ). The treadmill speed and elevation was the same as in the normoxic experiments, except in the animal at $380 \mathrm{mmHg}$. This animal was exercised at $5 \mathrm{~km} /$ $h$ at $20 \%$ treadmill elevation.

Statistical methods. Unless otherwise stated, base-line values are the mean $\pm 1 S D$ of all measurements obtained over a period of $1-2 h$ before exercise. In the hypobaric experiments, the data collected before exercise but after decompression are expressed as the mean $\pm 1 \mathrm{SD}$ of all measurements obtained over a period of at least $2 \mathrm{~h}$ before the onset of exercise. The data obtained during exercise are expressed as the mean $\pm 1 S D$ of all the measurements made at 10 -min intervals during exercise. To determine the significance of any changes observed with decompression or exercise, we used the paired Student's $t$ test. $P<0.05$ were considered significant.

To determine the relation between cardiac output and lung lymph flow, we performed a linear regression analysis with a digital computer.

\section{Results}

Normoxic exercise. The animals ran for 15-85 min depending on the individual animal, the treadmill speed, and elevation. A typical experiment is illustrated in Fig. 1 while Table I contains mean data for the nine experiments in the six animals. Exercise caused on average a $100 \%$ increase in cardiac output and a $140 \%$ increase in lung lymph flow $(P<0.01)$. Lymph flow and cardiac output returned to base line during 20 min of rest. The lymph to plasma concentration ratio $(1 / p)^{1}$ for total protein decreased by $12 \%$ during exercise $(P<0.05)$ and remained at that level at the 20 -min postexercise point $(P<0.05)$. There was no significant change in left atrial pressures and although there was a trend towards a slight increase in pulmonary arterial pressure, this failed to reach significance. There was no significant change in the calculated pulmonary artery to left atrial pressure gradient. Fig. 2 shows the relation between cardiac output and lymph flow during exercise and in the 20-min postexercise period. The increase in lymph flow correlated with the increase in cardiac output $(r=0.67, P<0.01$ ). When the one animal, which had an unexplained greater increase in lymph flow, is excluded, there is an even better correlation between cardiac output and lymph flow $(r=0.87, P=<0.01)$. Fig. 3 shows the effect of exercise on the $1 / \mathrm{p}$ for total protein, albumin, $\mathrm{IgG}$, and IgM. On the same graphs, we have also plotted data from previously published experiments in which lymph flow was increased by inflating a balloon in the left atrium (23). Exercise caused a minimal but significant reduction in $1 / p$ of total protein and albumin, but no detectable change in $1 / p$ of IgG or IgM. These observations contrast with the abrupt fall in $1 / p$ ratios that are produced by increased left atrial pressure alone.

Blood gas tensions, $\mathrm{pH}$, and mixed venous lactate produced during exercise are contained in Table II. Exercise caused an increase in $\mathrm{P}_{\mathrm{a}} \mathrm{O}_{2}(P<0.01)$ and a reduction in $\mathrm{P}_{\mathrm{a}} \mathrm{CO}_{2}(P<0.005)$,

1. Abbreviations used in this paper: $1 / \mathrm{p}$, lymph to plasma concentration ratio. 


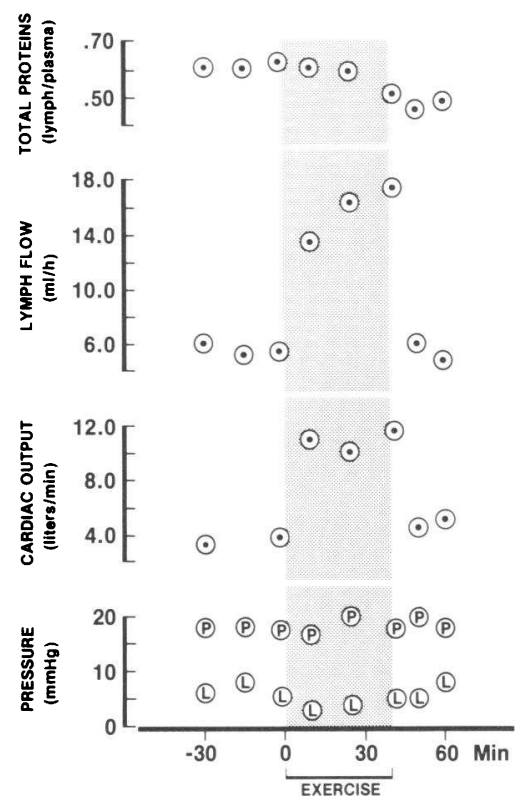

Figure 1. Changes in cardiac output, lung lymph flow, $1 / \mathrm{p}$ total protein ratio, and mean left atrial, (1), and pulmonary arterial, $(\mathbb{P}$, pressures during one exercise experiment under normobaric conditions.

but no change in pHa. In pulmonary arterial blood, there was a significant decrease in $\mathrm{PCO}_{2}$ and $\mathrm{PO}_{2}(P<0.05)$. There was no change in mixed venous $\mathrm{pH}$. There was a threefold increase in mixed venous plasma lactate concentration $(P<0.01)$.

Hypobaric hypoxia. Despite the hypoxia, the sheep at 430 $\mathrm{mmHg}$ barometric pressure $(4,500 \mathrm{~m})$ managed to run for $24-$ $48 \mathrm{~min}$ at $3-5 \mathrm{~km} / \mathrm{h}$ and $5 \%$ elevation. The sheep exposed to $380 \mathrm{mmHg}(5,500 \mathrm{~m})$ ran for $10 \mathrm{~min}$ at $5 \mathrm{~km} / \mathrm{h}$ and $20 \%$ elevation. Except for the blood gas tensions, the results are

Table I. Changes in Hemodynamics and Lung Lymph during Normoxic Exercise

\begin{tabular}{|c|c|c|c|c|c|}
\hline & $\begin{array}{l}\text { Cardiac } \\
\text { output }\end{array}$ & $\begin{array}{l}\text { Lymph } \\
\text { flow }\end{array}$ & Total protein & P̄pa & Pिla \\
\hline & liter/min & $m l / h$ & $l / p$ & $m m H g$ & $m m H g$ \\
\hline Base line & $3.9 \pm 1.0$ & $4.0 \pm 2.1$ & $0.51 \pm 0.11$ & $16 \pm 6$ & $9 \pm 3$ \\
\hline Exercise & $7.8 \pm 2.5 \ddagger$ & $9.6 \pm 5.2 \ddagger$ & $0.45 \pm 0.10^{*}$ & $18 \pm 4$ & $8 \pm 4$ \\
\hline Postexercise & $3.7 \pm 1.0$ & $3.7 \pm 2.0$ & $0.46 \pm 0.08^{*}$ & $17 \pm 4$ & $9 \pm 3$ \\
\hline
\end{tabular}

P̄pa, mean pulmonary artery pressure; $\bar{P}$ la, mean left atrial pressure. Values are given as mean $\pm \mathrm{SD}, n=9$.

Base line refers to the average of all measurements obtained during the 1-2 $\mathrm{h}$ interval prior to exercise. Exercise values are the average data during the exercise period and postexercise values are those obtained during the $20 \mathrm{~min}$ immediately following exercise.

*, different from base line, $P<0.05$.

$\ddagger$, different from base line, $P<0.01$.

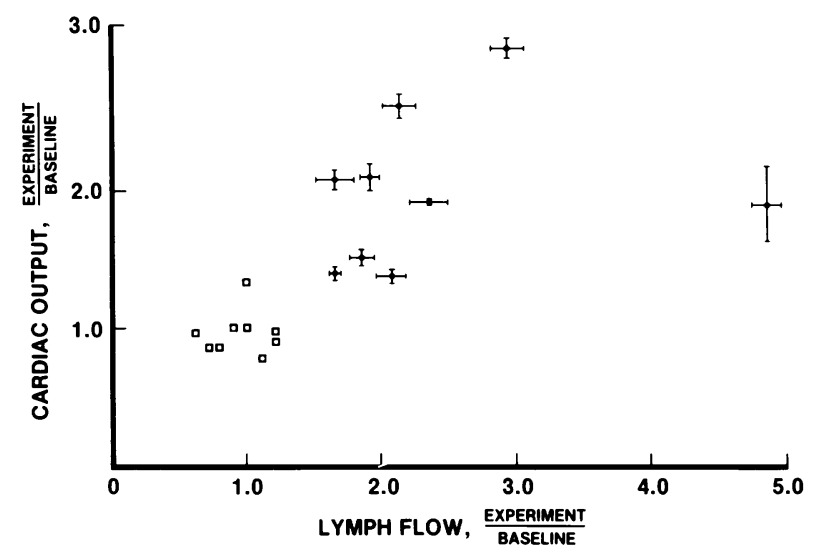

Figure 2. Relation between change in cardiac output and change in lung lymph flow during exercise $(\bullet)$ and the 20 -min postexercise point (ㅁ). Each exercise data point is the mean $\pm \mathrm{SE}$ of all the cardiac output and lymph flow measurements made during exercise in an individual animal. With the one outrider point removed, the regression line has the form $y=0.883 x+0.14$ where $r=0.874, n$ $=17$, and $P<0.01$. With that point included, $y=0.435 x+0.74$, where $r=0.67, n=18$, and $P<0.01$.

essentially the same as in the normoxic exercise experiments. Table III contains the mean hemodynamic data obtained during the $1 \mathrm{~h}$ base-line period under normobaric conditions, $2 \mathrm{~h}$ during

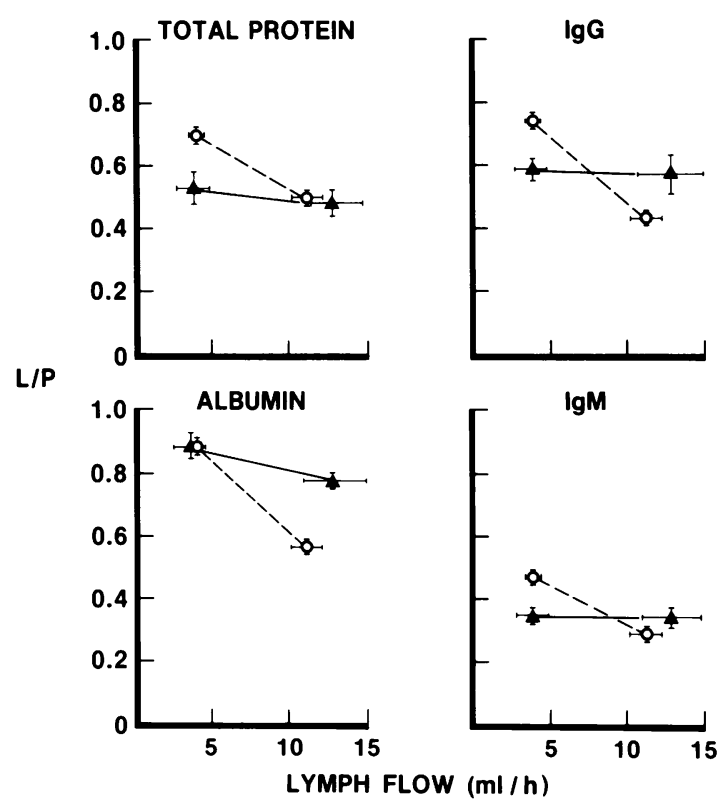

Figure 3. The effect of exercise $(\Delta)$ and inflation of a left atrial balloon catheter $(0,23)$ on the $1 / p$ of endogenous proteins (mean $\pm S E$ ). The elevation in left atrial pressure increased lung lymph flow with an abrupt fall in $1 / p$ for all sized proteins. Exercise resulted in a comparable increase in lymph flow but in contrast there was minimal (total protein, albumin) or no change (IgG, IgM) in $1 / p$. 
Table II. Changes in Blood Gas Tensions, $\mathrm{pH}$, and Lactate during Normoxic Exercise

\begin{tabular}{|c|c|c|c|c|c|c|c|}
\hline & \multirow{2}{*}{$\begin{array}{l}\text { Plasma } \\
\text { lactate }\end{array}$} & \multicolumn{3}{|l|}{ Mixed venous } & \multicolumn{3}{|c|}{ Systemic arterial } \\
\hline & & $\mathrm{pH}$ & $\mathrm{PCO}_{2}$ & $\mathrm{PO}_{2}$ & $\mathrm{pH}$ & $\mathrm{PCO}_{2}$ & $\mathrm{PO}_{2}$ \\
\hline & $m M / l i t e r$ & & $\mathrm{mmHg}$ & $\mathrm{mmHg}$ & & $m m H g$ & $m m H g$ \\
\hline Base line & $0.5 \pm 0.3$ & $7.45 \pm 0.05$ & $44 \pm 4$ & $40 \pm 3$ & $7.52 \pm 0.04$ & $35 \pm 5$ & $84 \pm 8$ \\
\hline Exercise & $1.6 \pm 0.7 \ddagger$ & $7.47 \pm 0.06$ & $39 \pm 6^{*}$ & $37 \pm 6^{*}$ & $7.54 \pm 0.07$ & $30 \pm 5 \ddagger$ & $87 \pm 6 \ddagger$ \\
\hline Postexercise & $0.9 \pm 0.4$ & $7.48 \pm 0.07$ & $37 \pm 6^{*}$ & $41 \pm 2$ & $7.51 \pm 0.05$ & $31 \pm 4^{*}$ & $83 \pm 5$ \\
\hline
\end{tabular}

Mean values $\pm \mathrm{SD}$ during base line, exercise, and the $20 \mathrm{~min}$ postexercise periods for mixed venous plasma lactate, and venous and arterial $\mathrm{pH}$, $\mathrm{PCO}_{2}$, and $\mathrm{PO}_{2}$ in nine experiments. *, different from base line, $P<0.05$; , different from base line, $P<0.01$.

hypobaric conditions, the hypobaric exercise period, and the hypobaric postexercise period. Decompression caused an immediate increase in pulmonary arterial pressure in all sheep $(P$ $<0.01$ ), but no significant change in left atrial pressure, cardiac output, lymph flow, or $1 / \mathrm{p}$ for total protein. Exercise caused a $60 \%$ increase in cardiac output $(P<0.01)$, a $90 \%$ increase in lymph flow $(P<0.005)$, and an $11 \%$ reduction in the $1 / \mathrm{p}$ total protein ratio $(P<0.05)$. Table IV contains the $1 / p$ concentration ratios for albumin, IgG, and IgM before and after exercise. There was no significant change. There was no exercise-induced change in left atrial or pulmonary arterial pressures. All except the $1 / \mathrm{p}$ for total protein returned to the preexercise values during the postexercise rest period $(P<0.05)$.

Decompression caused a reduction in venous and arterial $\mathrm{PO}_{2}$ and $\mathrm{PCO}_{2}(P<0.01)$, but no significant change in $\mathrm{pH}$ or plasma lactate concentration (Table $\mathrm{V}$ ). During hypobaric exercise, arterial $\mathrm{PO}_{2}$ increased slightly $(P<0.05)$; there was a further decrease in arterial and venous $\mathrm{PCO}_{2}(P<0.05)$ and an increase in arterial and venous $\mathrm{pH}(P<0.05)$. Mixed venous plasma lactate concentration doubled $(P<0.01)$. Arterial $\mathrm{pH}$ and $\mathrm{PO}_{2}$ returned to preexercise values during the rest period.

\section{Discussion}

Our study demonstrates that exercise is associated with a significant increase in lung lymph flow. The cause of the increased lymph flow is not clear although there are data from this and other studies to favor one mechanism over others. An increased lymph flow from any organ can be secondary to a change in transvascular oncotic or hydrostatic pressure gradient, an increase in the permeability of the fluid exchange vessels to water and protein, or an increase in perfused surface area.

Could an increase in pulmonary microvascular hydrostatic pressure during exercise explain the increased lymph flow? We did not observe a significant increase in left atrial or pulmonary arterial pressure during exercise. Neither was there a significant increase in the pulmonary arterial to left atrial pressure gradient. The effect of exercise on mean pulmonary arterial pressure is varied and depends upon the increase in cardiac output, duration of exercise, and the age of the animal $(1,2,3,24)$. The fact that there was only a trend towards an increase in mean pulmonary arterial pressure in our normoxic exercise experiments is consistent with previous observations because there was only a modest increase in cardiac output. The lack of a significant increase in the transpulmonary vascular pressure gradient despite a doubling of cardiac output indicates a reduction in pulmonary vascular resistance. It is possible that the increased blood flow caused a greater transmission of upstream pressure to the fluid exchange vessels of the lungs. This could result in an increase in fluid filtration and lung lymph flow, and may have been responsible for the slight decrease in $1 / p$ for total protein. Although this mechanism may have contributed to a small degree

Table III. Changes in Hemodynamics and Lung Lymph during Exercise Under Hypobaric Conditions

\begin{tabular}{llllll}
\hline & Cardiac output & Lymph flow & Total protein & Pिpa & P'a \\
\hline & Liter/min & $m l / h$ & $1 / p$ & $m m H g$ & $m$ \\
Base-line normobaria & $4.3 \pm 0.1$ & $3.1 \pm 1.3$ & $0.61 \pm 0.07$ & $18 \pm 3$ & $8 \pm 1$ \\
Hypobaria & $4.5 \pm 0.7$ & $4.2 \pm 1.6$ & $0.59 \pm 0.08$ & $30 \pm 5^{*}$ & $7 \pm 3$ \\
Exercise hypobaria & $7.1 \pm 1.2 \S$ & $8.0 \pm 3.7 \S$ & $0.53 \pm 0.07 \ddagger$ & $28 \pm 6^{*}$ & $6 \pm 3$ \\
Postexercise hypobaria & $4.8 \pm 0.4$ & $4.4 \pm 3.7$ & $0.54 \pm 0.09 \ddagger$ & $31 \pm 13^{*}$ & $7 \pm 5$ \\
\hline
\end{tabular}

$\overline{\mathrm{P}}$ pa, mean pulmonary artery pressure; $\overline{\mathrm{P}} \mathrm{a}$, mean left atrial pressure. Values are given as mean $\pm \mathrm{SD}, \mathrm{n}=5$. *, different from base line during normobaria, $P<0.01 ; \ddagger$, different from hypobaria alone, $P<0.05 ; \S$, different from hypobaria alone, $P<0.01$. 
Table IV. Lymph/Plasma Concentration Ratio for Endogenous Proteins during Hypobaric Exercise

\begin{tabular}{llll}
\hline & $1 / \mathrm{p}$ albumin & $1 / \mathrm{p} \mathrm{IgG}$ & $1 / \mathrm{p} \mathrm{IgM}$ \\
\hline $\begin{array}{c}\text { Base line } \\
\text { hypobaria }\end{array}$ & $0.71 \pm 0.08$ & $0.42 \pm 0.1$ & $0.29 \pm 0.18$ \\
$\begin{array}{c}\text { Exercise } \\
\text { hypobaria }\end{array}$ & $0.67 \pm 0.08$ & $0.42 \pm 0.05$ & $0.27 \pm 0.16$
\end{tabular}

Values are given as mean $\pm \mathrm{SD}, n=5$.

to the increase in lymph flow, it is unlikely to be a major factor in view of our data on lymph protein concentration and our findings during hypoxia. It is well established that an increase in pulmonary microvascular filtration pressure causes an increase in lung lymph flow and a marked reduction in the $1 / \mathrm{p}$ of small and large proteins. The results of such an experiment (23) with increased vascular pressure are illustrated in Fig. 3 along with our results of the effect of exercise on $1 / p$ total protein, albumin, $\mathrm{IgG}$, and IgM. Although there was a significant reduction in $1 / \mathrm{p}$ for total protein and albumin during exercise, they are less than those produced by increased vascular pressure alone. In addition, during exercise there was no change in the $1 / p$ of $\operatorname{lgG}$ and IgM. These differences are further supported by data illustrated in Fig. 4 where we have compared the effect of exercise on lymph flow and $1 / p$ of total protein with three separate reports in which left atrial pressure was increased $(23,25,26)$.

An increase in surface area alone with no change in the permeability of the exchange vessel or the filtration pressure would intuitively cause an increase in lymph flow equal to the increase in surface area. There would be no change in the lymph protein concentration.

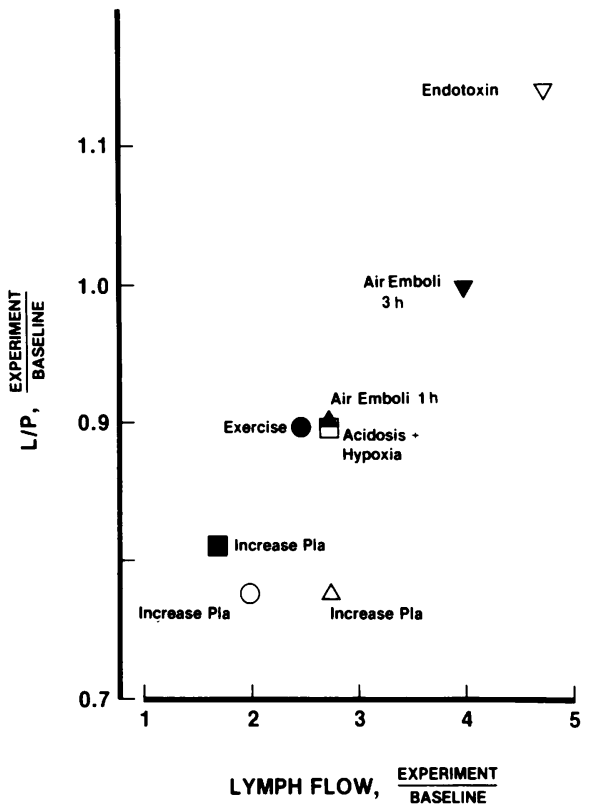

Figure 4. The relation between the change in $1 / p$ concentration ratio of total protein and the change in lymph flow after various insults to the lungs. Pिla, left atrial pressure. $\Delta$, Increased Pिla, $11 \mathrm{mmHg}(23) . \circ$,

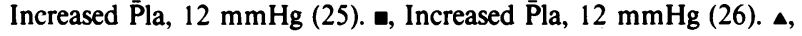
Air emboli infusion for $1 \mathrm{~h} \mathrm{(26).} \nabla$, Air emboli infusion for $3 \mathrm{~h}$ (26). $\square$, Hypercapnic-hypoxia (23). $\nabla$, E-coli endotoxin (55). ๑, Exercise (present study).

The increased lung lymph flow with increased left atrial pressure is not solely due to an increase in vascular filtration pressure. It is clear from several studies $(27,28,29)$ that an increased left atrial pressure also causes recruitment of alveolar

Table V. Changes in Blood Gas Tensions, pH, and Lactate during Hypobaria and Exercise**

\begin{tabular}{|c|c|c|c|c|c|c|c|}
\hline & \multirow{2}{*}{$\begin{array}{l}\text { Plasma } \\
\text { lactate }\end{array}$} & \multicolumn{3}{|l|}{ Mixed venous } & \multicolumn{3}{|c|}{ Systemic arterial } \\
\hline & & $\mathrm{pH}$ & $\mathrm{PCO}_{2}$ & $\mathrm{PO}_{2}$ & $\mathrm{pH}$ & $\mathrm{PCO}_{2}$ & $\mathrm{PO}_{2}$ \\
\hline & $m M / l i t e r$ & & $m m H g$ & $m m H g$ & & $m m H g$ & $m m H g$ \\
\hline \multicolumn{8}{|l|}{ Base line } \\
\hline normobaria & $0.9 \pm 0.3$ & $7.52 \pm 0.03$ & $43 \pm 3$ & $38 \pm 1$ & $7.60 \pm 0.05$ & $34 \pm 5$ & $81 \pm 4$ \\
\hline Hypobaria & $1.1 \pm 0.4$ & $7.57 \pm 0.05$ & $32 \pm 4^{*}$ & $27 \pm 2 \ddagger$ & $7.60 \pm 0.04$ & $28 \pm 3 \ddagger$ & $39 \pm 4 \ddagger$ \\
\hline \multicolumn{8}{|l|}{ Exercise } \\
\hline hypobaria & $2.3 \pm 1.1^{11}$ & $7.58 \pm 0.06$ & $29 \pm 4 \S$ & $25 \pm 2$ & $7.66 \pm 0.02 \S$ & $25 \pm 4 \S$ & $42 \pm 4 \S$ \\
\hline \multicolumn{8}{|l|}{ Postexercise } \\
\hline hypobaria & $1.9 \pm 1.2 \S$ & $7.57 \pm 0.06$ & $31 \pm 1^{*}$ & $28 \pm 3$ & $7.61 \pm 0.04$ & $28 \pm 1 \ddagger$ & $42 \pm 2 \S$ \\
\hline
\end{tabular}

Values are given as mean $\pm \mathrm{SD} .{ }^{*}$, different from base line, $P<0.05$; $\ddagger$ different from base line, $P<0.01 ; \S$, different from hypobaria, $P$ $<0.05$; ", different from hypobaria, $P<0.01 ; * *, 430 \mathrm{mmHg}(n=4)$. The one animal that was decompressed to $380 \mathrm{mmHg}$ is excluded from the blood gas data only. The $\mathrm{PaO}_{2}, \mathrm{PaCO}_{2}$, and pHa in this animal were 86, 35, and 7.54 (normobaria); 34, 23, and 7.57 (hypobaria); 33,22 , and 7.58 (hypobaric exercise), and 32, 22, and 7.56 (hypobaric postexercise). Exercise caused an increase in venous plasma lactate from 1.6 to 4 $\mathrm{mM} /$ liter. 
capillaries. This increased vascular surface area would augment the increased lymph flow caused by increased filtration pressure. The relative effects of increased surface area and increased filtration pressure on the increased lymph flow with left atrial hypertension is not known; the major factor is likely to be increased filtration pressure.

If the increased lymph flow with exercise was caused by a greater transmission of upstream pressure to the pulmonary fluid exchange vessels during exercise, then this effect should be more evident when hypoxic animals exercise. Holtgren (20) has suggested this as a mechanism in high altitude pulmonary edema. There is no evidence to support this from our experiments. The changes in $1 / p$ for albumin, IgG, and IgM were the same in animals exercising at sea level and during hypobaric hypoxia. The hypobaric experiments also confirmed previous reports by us $(30)$ and other workers $(31,32)$ that hypoxia has no effect on lung lymph flow in sheep at rest. This serves to emphasize again that the site of hypoxia-induced pulmonary vasoconstriction in adult sheep is upstream from the fluid exchange vessels.

The increased lymph flow was not secondary to a decrease in oncotic pressure gradient $(\Delta \pi)$. The slight reduction in $1 / p$ total protein was caused by a slight reduction in lymph protein concentration sometimes combined with a slight increase in plasma protein concentration. This increase in $\Delta \pi$ would tend to reduce, not increase lymph flow.

Our data could be explained on the basis of increased pulmonary capillary permeability. Indeed, the increase in protein clearance produced by exercise is the same as observed after 1 $\mathrm{h}$ of air microembolization and the same as produced by acidosis and hypoxia (Fig. 4), which are insults believed to increase pulmonary vascular permeability $(23,26)$. If there was an increase in vascular permeability, it would have to be rapidly reversible because the increased lymph flow secondary to exercise returned to base line within minutes of stopping the exercise in both normoxic and hypoxic animals. The reduction in $1 / p$ of albumin without a similar reduction in $1 / p$ of $\operatorname{lgG}$ or IgM indicates that exercise increases the transport of large molecular weight proteins to a greater extent than it does for albumin. Two possible explanations for this latter observation are that pore-stretching occurred secondary to vascular dilatation, or increased vesicular transport of large proteins occurred secondary to an increase in microvascular pressure.

Wasserman et al. (33) first suggested the possibility of a vascular pressure-related increase in capillary permeability, and Pietra et al. (34) have observed an increased transport of large proteins across pulmonary vascular endothelium in isolated, perfused dog lungs but only with very high vascular pressures. Parving et al. (35) have recently suggested that a similar phenomenon occurs in the systemic circulation with increased vascular pressure in man. On the other hand, there is no evidence that increased pulmonary vascular pressure $(36,37)$ causes porestretching in the intact sheep lungs.

There is evidence that increased vascular pressure causes an increase in transendothelial vesicular transport in isolated dog lungs (38). Vesicular transport of large proteins may correspond to the large pore system derived from pore modeling (39), and therefore, an increase in vesicular transport would cause a selective increase in transport of large molecular weight proteins. Although either pore stretching or increased vesicular transport could explain our data, we have no evidence to support or refute either mechanism.

Another explanation for the slight fall in $1 / p$ for albumin in our studies is that exercise caused recruitment of new vascular channels with different permeability characteristics to water and protein compared with those that are perfused at rest. This mechanism has been used to explain the increased fluid filtration observed in pig lungs subjected to hypoxia (40).

The most likely explanation for our data is that the increased lymph flow resulted primarily from an increase in perfused microvascular surface area. It is well established from measurements of carbon monoxide uptake by the lung (6), and changes in mean transit time of tracers through the lung $(4,5)$ that exercise causes a two- to threefold increase in lung blood volume in animals and man. The relative contribution of capillary dilation and capillary recruitment to this increased pulmonary blood volume is debated (41). Regardless of the mechanism, it would result in a significant increase in perfused microvascular surface area and comparable increase in fluid movement out of vessels. If there were no changes in Starling's forces or increase in capillary permeability, there would be no change in lymph protein concentration relative to plasma. The increase in lung lymph flow with exercise paralleled the increase in cardiac output, as did the return of lymph flow to base line with return of cardiac output to base line. Although we cannot measure the surface area of the fluid exchanging vessels within the lung, we speculate that the same relation would exist between lymph flow and surface area as exists between lymph flow and cardiac output. The only data that does not completely fit with the explanation of increased surface area is the small reduction in $1 / p$ for total protein and albumin. Landolt et al. (42) also observed a small reduction in $1 / p$ of total protein after forcing the total cardiac output through $35 \%$ of the total lung mass in sheep. There was a modest increase in lung lymph flow after they resected lung tissue; this was most likely due to the tripling of the perfused pulmonary vascular bed in the remaining lung.

We cannot explain this small reduction in $1 / p$ total protein and albumin, but as already discussed, it could be secondary to greater transmission of upstream pressure to the fluid exchange vessels or to different permeability characteristics of the newly recruited vessels.

During exercise the sheep increased their respiratory rate. It is unlikely, however, that the coexistent increased frequency of pleural pressure swings is responsible for the stable, persistent increase in lung lymph flow that we observed during exercise. We have previously demonstrated that rhythmic inflation and deflation of the lung is not required for normal lung lymphatic function (43) and others have demonstrated that eucapneic hyperventilation does not increase the flow of lymph from the lungs of dogs (44). 
In awake hypercapnic sheep, the associated marked increase in ventilation is accompanied by only a $2-\mathrm{mmHg}$ reduction in mean pleural balloon pressure (23). Exercise in man has also been shown to produce only a slight reduction in mean transpulmonary pressure $(45,46)$. These changes in transpulmonary pressure are far less than those reported to cause an increase in transvascular fluid movement (47). In these and other experiments in sheep, (30-32) hyperventilation secondary to hypoxia also had no effect on lung lymph flow. Finally, in many of the experiments reported in this study, lung lymph flow had returned to normal after the end of exercise, despite the fact that the animals were still hyperventilating.

Acute pulmonary edema occurs in $\sim 4 \%$ of individuals who ascend to altitudes above $3,200 \mathrm{~m} \mathrm{(20)}$. The edema is invariably associated with exercise and usually occurs $24-72 \mathrm{~h}$ after ascent. Various mechanisms have been suggested. One of the most tenable is that hypoxia causes a nonuniform distribution of increased pulmonary vascular resistance in some individuals such that with exercise there is over perfusion of some capillary units with subsequent increased fluid filtration (20). Three of our exercise experiments were conducted after the animals had been at simulated altitude of 4,550 or $5,500 \mathrm{~m}$ for $24 \mathrm{~h}$ and two were performed within $2 \mathrm{~h}$ of decompression. None of these experiments showed an increased lymph flow over and above that found in the same animals after exercise at sea level. We conclude, that at least in sheep, hypobaric hypoxia and exercise do not cause a sufficient increase in lung fluid transport to produce clinical pulmonary edema.

It is uncertain whether lung water content changes during exercise. Vigorous exercise in man has been shown to produce an increased residual volume $(12,13)$, a decreased thoracic electrical impedence (14), and an increased closing capacity (48). Similar changes have also been reported in man with hypobaric hypoxia $(10,11)$. This has been used as indirect evidence for increased extravascular lung water and peribronchial edema. Indeed, there have been anecdotal reports of acute pulmonary edema occurring after very vigorous exercise in previously healthy elite athletes (17). On the other hand, Marshall et al. (49) have made direct measurements of lung water after vigorous exercise in dogs and were unable to show any increase in wet weight/dry weight ratio. Similarly, Vaughan et al. (50) made measurements of lung water by indicator dilution after exercise in man and concluded that there was no detectable increase in extravascular lung water.

The relation between increased extravascular lung water and increased lung lymph flow is not clear, particularly with modest increases in lymph flow, and there are only limited data available. At very high lymph flow produced by a calculated microvascular pressure of $50 \mathrm{cmH}_{2} \mathrm{O}$, Erdmann et al. (36) detected a $25 \%$ increase in extravascular lung water. No significant change in wet weight/dry weight ratio was detected until microvascular pressure and lymph flow had doubled. Pine et al. (51) found a curvilinear relationship between lung water content and right duct lymph flow in dogs after $\alpha$-naphthylthiourea.

Extravascular lung water accumulates first in perivascular and peribronchial spaces (52), and thus, even a small increase in lung water below the range of sensitivity of the indicator dilution or the wet weight/dry weight ratio methods might cause physiologic changes, such as small airway closure and maldistribution of ventilation. We have shown this to occur in human subjects after rapid infusion of saline and with no other evidence of increased lung water (53). We subsequently showed that these changes in small airways were not caused by changes in intrathoracic blood volume (54) and were therefore probably caused by peribronchial edema. The point that we are making is that if moderate exercise in humans produces the same increase in lung fluid exchange as detected in our sheep, this may increase extravascular lung water sufficiently to explain the physiological changes in the lung found after exercise $(12,14)$ but not sufficiently to be detected by indicator dilution or X-ray techniques.

An increase in lung lymph flow with no change in $1 / p$ for protein is usually interpreted as indicating an increase in capillary permeability. These alterations in lung water and solute movement can also result from an increase in surface area; however, this parameter is difficult to measure. The changes in lymph flow and $1 / p$ for protein that we observed during exercise could be secondary to increased permeability but are more likely simply due to an increase in perfused surface area. These experiments serve to emphasize the magnitude of the change in lymph flow that can occur with changes in pulmonary capillary surface area. Our data suggests that lung lymph flow can increase up to threefold merely from an increase in surface area (Fig. 2). This should be borne in mind when interpreting lymph flow data.

\section{Acknowledgments}

This work could not have been performed without the able technical assistance of Ami Thind and L. Brooker.

These investigations were supported by a grant in aid from the Medical Research Council of Canada (MA-7893).

\section{References}

1. Hickam, J. B., and W. H. Cargill. 1948. Effect of exercise on cardiac output and pulmonary arterial pressure in normal persons and in patients with cardiovascular disease and pulmonary emphysema. J. Clin. Invest. 27:10-23.

2. Riley, R. L., A. Himmelstein, H. L. Motley, H. M. Weiner, and A. Cournand. 1948. Studies of the pulmonary circulation at rest and during exercise in normal individuals and in patients with chronic pulmonary disease. Am. J. Physiol. 152:372-382.

3. Dexter, L., J. L. Whittenberger, F. W. Haynes, W. T. Goodale, R. Gorlin, and C. G. Sawyer. 1951. Effect of exercise on circulatory dynamics of normal individuals. J. Appl. Physiol. 3(8):439-453.

4. Yu, P. N. 1969. Pulmonary Blood Volume in Health and Disease. Lea and Febiger, Philadelphia. 122-138.

5. Braunwald, E., and E. R. Kelly. 1960. The effects of exercise on central blood volume in man. J. Clin. Invest. 39:413-419.

6. Johnson, R. L., Jr., W. S. Spicer, J. M. Bishop, and R. E. Forster. 1960. Pulmonary capillary blood volume, flow and diffusing capacity during exercise. J. Appl. Physiol. 15(5):893-902. 
7. White, J. C., M. E. Field, and C. K. Drinker. 1933. On the protein content and normal flow of lymph from the foot of the dog. Am. J. Physiol. 103:34-44.

8. Drinker, C. K., M. F. Warren, F. W. Maurer, and J. D. McCarrell. 1940. The flow, pressure and composition of cardiac lymph. Am. J. Physiol. 130:43-55.

9. Goresky, C. A., R. F. P. Cronin, and B. E. Wangel. 1969. Indicator dilution measurements of extravascular water in the lungs. J. Clin. Invest. 48:487-501.

10. Jaeger, J. J., J. T. Sylvester, A. Cymerman, J. J. Berberich, J. C. Denniston, and J. T. Maher. 1979. Evidence for increased intrathoracic fluid volume in man at high altitude. J. Appl. Physiol. Respir. Environ. Exercise Physiol. 47(4):670-676.

11. Coates, G., G. Gray, A. Mansell, C. Nahmias, A. Powles, J. Sutton, and C. Webber. 1979. Changes in lung volume, lung density, and distribution of ventilation during hypobaric decompression. J. Appl. Physiol. Respir. Environ. Exercise Physiol. 46(4):752-755.

12. Maron, M. B., L. H. Hamilton, and M. G. Maksud. 1979. Alterations in pulmonary function consequent to competitive marathon running. Med. Sci. Sports. II(3):244-249.

13. Buono, M. J., S. H. Constable, A. R. Morton, T. C. Rotkis, P. R. Stanforth, and J. H. Wilmore. 1981. The effect of an acute bout of exercise on selected pulmonary function measurements. Med. Sci. Sports Exercise. 13(5):290-293.

14. Buono, M. J., J. H. Wilmore, and F. B. Roby, Jr. 1982. Evidence of increased thoracic extra vascular fluid following intense exercise in man. Physiologist. 25:201. (Abstr.)

15. Goresky, C. A., J. W. Warnica, J. H. Burgess, and B. E. Nadeau. 1975. Effect of exercise on dilution estimates of extravascular lung water and on the carbon monoxide diffusing capacity in normal adults. Circ. Res. 37:379-389.

16. Marshall, B. E., R. L. Teichner, T. Kallos, H. J. Sugerman, M. Q. Wyche, Jr., and K. R. Tantum. 1971. Effects of posture and exercise on the pulmonary extravascular water volume in man. J. Appl. Physiol. 31:375-379.

17. McKechnie, J. K., W. P. Leary, T. D. Noakes, J. C. Kallmeyer, E. T. M. MacSearraigh, and L. R. Olivier. 1979. Acute pulmonary oedema in two athletes during a $90-\mathrm{km}$ running race. $S$. Afr. Med. J. 56:261-265.

18. Houston, C. S. 1960. Acute pulmonary edema of high altitude. N. Engl. J. Med. 263:478-480.

19. Singh, I., C. C. Kapila, P. K. Khanna, R. B. Nanda, and B. D. P. Rao. 1965. High altitude pulmonary edema. Lancet. 229-234.

20. Hultgren, H. N. 1978. High altitude pulmonary edema. In Lung Water and Solute Exchange. N. C. Staub, editor. Marcel Dekker, Inc., Lenfant Series, NY. 7:437-464.

21. Staub, N. C., R. Bland, K. Brigham, R. Demling, J. Erdmann, and W. Woolverton. 1975. Preparation of chronic lung lymph fistulas in sheep. J. Surg. Res. 19:315-320.

22. O'Brodovich, H. M., M. Andrew, R. Silver, and G. Coates. 1983. Assessment of the coagulation cascade during air microembolization of the lung. J. Appl. Physiol. Respir. Environ. Exercise Physiol. 55:17431747.

23. O'Brodovich, H. M., S. A. Stalcup, L. M. Pang, J. S. Lipset, and R. B. Mellins. 1981. Bradykinin production and increased pulmonary endothelial permeability during acute respiratory failure in unanesthetized sheep. J. Clin. Invest. 67:514-522.

24. Ehrsam, R. E., A. Perruchoud, M. Oberholzer, and F. Burkart The influence of age on pulmonary hemodynamics at rest and during supine exercise. Clin. Sci. (in press).
25. Bowers, R. E., K. L. Brigham, and P. J. Owen. 1977, Salicylate pulmonary edema: the mechanism in sheep and review of the clinical literature. Am. Rev. Respir. Dis. 115:261-268.

26. Ohkuda, K., K. Nakahara, A. Binder, and N. C. Staub. 1981. Venous air emboli in sheep: reversible increase in lung microvascular permeability. J. Appl. Physiol. Respir. Environ. Exercise Physiol. 51(4):887-894.

27. Glazier, J. B., J. M. Hughes, J. E. Maloney, and J. B. West. 1969. Measurements of capillary dimensions and blood volume in rapidly frozen lungs. J. Appl. Physiol. 26:65-76.

28. Permutt, S., P. Caldini, A. Maseri, H. Palmer, T. Sasamori, and K. Zierler. 1969. Recruitment versus distensibility in the pulmonary vascular bed. In The Pulmonary Circulation and Interstitial Space. A. P. Fishman and H. H. Hecht, editors. University of Chicago Press, Chicago, IL. 375-388.

29. Wagner, W. W., and L. P. Latham. 1973. Vasomotion in the pulmonary microcirculation. In Small Vessel Angiography. S. K. Hilal, editor. Mosby, St. Louis. MO. 301-306.

30. Coates, G., L. W. Belbeck, and G. W. Gray. 1983. Hypobaric hypoxia does not affect lung fluid or protein exchange in awake adult sheep at rest. Can. J. Physiol. Pharmacol. 61(7):714-716.

31. Bland, R. D., R. H. Demling, S. L. Selinger, and N. C. Staub. 1977. Effects of alveolar hypoxia on lung fluid and protein transport in unanesthetized sheep. Circ. Res. 40:269-274.

32. Pang, L. M., H. M. O'Brodovich, R. B. Mellins, and S. A. Stalcup. 1982. Bradykinin-induced increase in pulmonary vascular permeability in hypoxic sheep. J. Appl. Physiol. Respirat. Environ. Exercise Physiol. 52(2):370-375.

33. Wasserman, K., L. Loeb, and H. S. Mayerson. 1955. Capillary permeability to macromolecules. Circ. Res. III:594-603.

34. Pietra, G. G., J. P. Szidon, M. M. Leventhal, and A. P. Fishman. 1969. Hemoglobin as a tracer in hemodynamic pulmonary edema. Science (Wash. DC). 166:1643-1646.

35. Parving, H.-H, N. Rossing, S. L. Nielsen, and N. A. Lassen. 1974. Increased transcapillary escape rate of albumin, IgG, and IgM after plasma volume expansion. Am. J. Physiol. 227(2):245-250.

36. Erdmann, A. J., III, T. R. Vaughan, Jr., K. L. Brigham, W. C. Woolverton, and N. C. Staub. 1975. Effect of increased vascular pressure on lung fluid balance in unanesthetized sheep. Circ. Res. 37:271-284.

37. Parker, R. E., R. J. Roselli, T. R. Harris, and K. L. Brigham. 1981. Effects of graded increase in pulmonary vascular pressure on lung fluid balance in unanesthetized sheep. Circ. Res. 49:1164-1172.

38. DeFouw, D. O., and P. B. Berendsen. 1978. Morphological changes in isolated perfused dog lungs after hydrostatic edema. Circ. Res. 43(1):72-82.

39. Renkin, E. M. 1978. Transport pathways through capillary endothelium. Microvasc. Res. 15:123-135.

40. Mitzner, W., and J. T. Sylvester. 1981. Hypoxic vasoconstriction and fluid filtration in pig lungs. J. Appl. Physiol: Respir. Environ. Exercise Physiol. 51(5):1065-1071.

41. Maseri, A., P. Caldini, P. Harward, R. C. Joshi, S. Permutt, and K. L. Zierler. 1972. Determinants of pulmonary vascular volume recruitment versus distensibility. Circ. Res. 31:218-228.

42. Landolt, C. C., M. A. Matthay, K. H. Albertine, P. J. Roos, J. P. Wiener-Kronish, and N. C. Staub. 1983. Overperfusion, hypoxia, and increased pressure cause only hydrostatic pulmonary edema in anesthetized sheep. Circ. Res. 52:335-341.

43. Jefferies, A. L., P. Hamilton, and H. O'Brodovich. 1983. Effect of high frequency oscillation on lung lymph flow. J. Appl. Physiol. Respir. Environ. Exercise. Physiol. 55:1373-1378.

44. Martin, D. J., F. A. Grimbert, P. Baconnier, and G. Benchetrit. 
1983. Effect of acute hypoxia on lung transvascular filtration in anaesthetized dogs. Bull. Eur. Physiopathol. Respir. 19:7-11.

45. Grimby, G., B. Saltin, and L. Wilhelmsen. 1971. Pulmonary flow-volume and pressure-volume relationship during submaximal and maximal exercise in young well-trained men. Bull. Physio-path. Respir. 7:157-168.

46. Stubbing, D. G., D. Pengelly, J. L. C. Morse and N. L. Jones. 1980. Pulmonary mechanics during exercise in normal males. J. Appl. Physiol. Respir. Environ. Exercise Physiol. 49(3):506-510.

47. Stalcup, S. A., and R. B. Mellins. 1977. Mechanical forces producing pulmonary edema in acute asthma. N. Engl. J. Med. 197(11):592596.

48. Miles, D. S., and R. J. Durbin. 1982. Alterations in small airways and diffusion capacity after a 5 mile run. Physiologist. 25:199. (Abstr.)

49. Marshall, B. E., L. R. Soma, and G. R. Neufeld. 1975. Lung water volume at rest and exercise in dogs. J. Appl. Physiol. 39(1):7-8.

50. Vaughan, T. R., Jr., E. M. DeMarino, and N. C. Staub. 1976. Indicator dilution lung water and capillary blood volume in prolonged heavy exercise in normal man. Am. Rev. Respir. Dis. 113:757-762.
51. Pine, M. B., P. M. Beach, T. S. Cottrell, M. Scola, and G. M. Turino. 1976. The relationship between right duct lymph flow and extravascular lung water in dogs given $\alpha$-naphthylthiourea. J. Clin. Invest. $58: 482-492$.

52. Staub, N. C., H. Nagano, and M. L. Pearce. 1967. Pulmonary edema in dogs, especially the sequence of fluid accumulation in lungs. J. Appl. Physiol. 22(2):227-240.

53. Coates, G., A. C. Powles, S. C. Morrison, J. R. Sutton, C. E. Webber, and C. J. Zylak. 1983. The effects of intravenous infusion of saline on lung density, lung volumes, nitrogen washout, computed tomographic scans, and chest radiographs in humans. Am. Rev. Respir. Dis. 127:91-96.

54. Coates, G., P. Powles, M. Basalygo, and G. Goeree. 1982. The effect of increased intra-thoracic blood volume on nitrogen washout lung volumes. Am. Rev. Respir. Dis. 125:241. (Abstr.)

55. Brigham, K. L., R. E. Bowers, and J. Haynes. 1979. Increased sheep lung vascular permeability caused by Escherichia coli endotoxin. Circ. Res. 45:292-297. 